DOI: 10.46294/ulplr-rdulp.siv lab

\title{
A SOBERANIA E A CONCORRÊNCIA FISCAL PREJUDICIAL NA UNIÃO EUROPEIA
}

\author{
ANTÓNIO GAMEIRO \\ PROFESSOR ASSOCIADO DA FACULDADE DE DIREITO DA UNIVERSIDADE \\ LUSÓFONA DE HUMANIDADES E TECNOLOGIAS
}

\begin{abstract}
In this Article, we intend to analyse the effects of fiscal sovereignty on the current state of harmful tax competition, in particular with regard to the corporate tax framework in the European Union, as the subject of polycentric research. This analysis will focus primarily on direct taxation on companies, regarded as the last stronghold of the fiscal sovereignty of the Member States.
\end{abstract}

KEYWORDS: Tax competition; harmful tax competition; direct taxation of companies; against economic ordination.

RESUMO: No presente artigo, pretendemos, analisar os efeitos da soberania fiscal no atual estado da concorrência fiscal prejudicial, em particular, relativamente ao quadro tributário das empresas na União Europeia, enquanto objeto de investigação policêntrica. Esta análise incidirá primordialmente sobre a tributação direta sobre as sociedades, considerada como o último reduto da soberania fiscal dos Estados-Membros.

KEYWORDS: Concorrência fiscal; Concorrência fiscal prejudicial; tributação direta das sociedades; contra ordenação económica.

SUMÁRIO: 1. Introdução; 2. As atribuições fiscais na União Europeia; 3. A soberania fiscal; 3.1 Os limites à soberania fiscal; 4. A concorrência fiscal Internacional; 5. A concorrência fiscal prejudicial; 5.1 As suas motivações e os seus sujeitos; 5.2 Os seus obstáculos, relevância e status quo; 6. A harmonização fiscal europeia - realidade ou mito?; 6.1 A harmonização fiscal e as sociedades; 7. Conclusões

\section{Introdução}

O nascimento e sedimentação de um Mercado Único no seio da União Europeia (UE), com a sua respetiva grandeza e importância, caracteriza-se, essencialmente, pelo nível de concorrência criada entre as empresas.

Neste sentido, as empresas adotam estratégias concorrenciais que thes permitam potenciar os seus resultados líquidos anuais e tentam intervir no mercado evitando práticas abusivas ou prejudiciais. A concorrência empresarial em geral, torna-se num mecanismo que visa a satisfação das necessidades coletivas e individuais, baseada numa relação de confiança entre os agentes económicos, entre empresas, pessoas e o Estado. Por isso, cada Estado elabora uma estratégia individual que possa potenciar o bom funcionamento do seu mercado através de uma política fiscal adequada, melhorando e suprimindo continuamente os obstáculos às transações comerciais intra-europeias, implementando e fiscalizando as regras de concorrência europeia, regulando através do seu ius imperii as distorções do mercado e as ajudas do Estado ao setor empresarial publico e privado, normalmente, por via da ação de uma entidade reguladora (Nabais, 2015: 116).

A grande preocupação nas economias modernas, é conseguir competir através da adoção de estratégias empresariais que permitam às empresas sobreviver no mercado concorrencial, sem incorrer em práticas abusivas ou prejudiciais para os demais agentes concorrentes.

Pretendemos, por isso, estudar e analisar precisamente, os efeitos da soberania fiscal no atual estado da concorrência fiscal prejudicial, em particular, relativamente ao quadro tributário das empresas na União Europeia, enquanto objeto de 
DOI: 10.46294/ulplr-rdulp.siv la6

investigação policêntrica. Esta análise incidirá primordialmente sobre a tributação direta sobre as sociedades, considerada como o último reduto da soberania fiscal dos Estados-Membros ${ }^{1}$.

Se por um lado, a existência de mecanismos fiscais de atração ou fixação de investimento interno e externo é justificada sobretudo, por razões tão dispares como a necessidade de poupança, de redução da tributação das empresas, redução da carga fiscal, aumento dos fatores de competitividade (Nabais, 2008: 10).

Por outro, a competitividade das empresas e das economias em geral assume uma função pública geral fundamental na políitica fiscal dos Estados, quer quanto à justiça fiscal, quer no que concerne à redistribuição da riqueza e ao equilíbrio social, económico e financeiro.

A política da concorrência foi criada enquanto disciplina legal (Sherman Act) ${ }^{2}$ , num momento histórico em que os cartéis eram enquadrados legitimamente pelos principais agentes económicos e pelos economistas em geral. Contudo, foi através, sobretudo, do desenvolvimento da teoria da concorrência imperfeita realizada por Robinson, Chamberlain e Fellner (Mateus, 2003), que se basearam nas contribuições Cournot e Bertrand (Motta, 2003), que a teoria da concorrência possibilitou a consagração e a fundamentação económica de políticas anti-trust. Assim, a criação da Autoridade da Concorrência e a Lei da Concorrência em Portugal (Mateus, 2003), bem como a existência de um amplo e profundo quadro legal europeu sobre práticas anti concorrenciais (Pires, 2019: 43), possibilitou também, entre nós, o seu grande desenvolvimento nos últimos 20 anos.

Sendo o objetivo da política de concorrência a manutenção de mercados concorrenciais, a políitica pública da concorrência motiva e encoraja a existência de uma forte eficiência industrial, uma afetação ótima dos recursos, a existência de investimento no progresso técnico e a motivação para uma constante flexibilidade e ajustamento à inovação tecnológica e industrial. Ora, esta regulação dos fatores competitivos, bem como dos fatores sociais, financeiros e fiscais é uma exigência das sociedades modernas, pois encontra-se a montante do potencial de crescimento económico e da própria e efetiva repartição e distribuição equitativa do rendimento nacional criado em cada ano em cada sociedade.

Na atual economia globalizada, em que os agentes económicos, mas os próprios Estados se encontram em condições de concorrência, é necessário cada vez mais garantir liberdade comercial, melhor repartição dos recursos e potenciar a transparência dos mercados para melhorar a proteção dos consumidores, o que apenas pode ser conseguido de uma forma justa por via da políica de concorrência fiscal (Dourado, 2010: 18).

No quadro da globalização que se vive desde os anos noventa, a concorrência fiscal tem exigido aos Estados-Membros profundas e permanentes reformas fiscais, por forma a colmatar as práticas de planeamento agressivo e delimitar as fronteiras do abuso fiscal ${ }^{3}$, criando condições para mais competitividade económica por via da permissão de uma maior liberdade de circulação de pessoas, bens capitais e serviços e, sobretudo, através da redução das taxas de imposto, da dupla tributação, dos benefícios e isenções fiscais e da tentativa de promoção de crescimento económico.

É por isso, que os Estados e os Estados-Membros em especial, tentam a todo o tempo criar e implementar medidas fiscais que permitem melhorar a competitividade nacional, garantindo a sua maior eficiência fiscal sistémica, potenciando que a concorrência fiscal ocorra afetando o valor dos bens sujeitos a imposto em comparação com as taxas de um outro sistema fiscal de outro Estado, criando um efeito negativo ou positivo nas receitas fiscais obtidas - conceito de concorrência fiscal prejudicial e concorrência fiscal benéfica (Pires, 2019: 237).

\section{As atribuições fiscais na UE}

Na União Europeia, os poderes fiscais quer do ponto de vista constitucional, quer do Direito Europeu, encontram-se radicados nas atribuições constitucionais dos Estados-Membros, uma vez que são elas mesmas quem legitimam originalmente o princípio do consentimento popular do pagamento de impostos e do bom funcionamento do mercado único (Nabais, 2008: 11). No quadro da necessidade de aprovação por unanimidade das matérias de natureza fiscal no seio da UE ${ }^{4}$

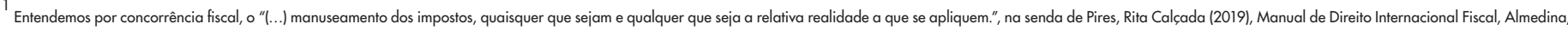
p. 236.

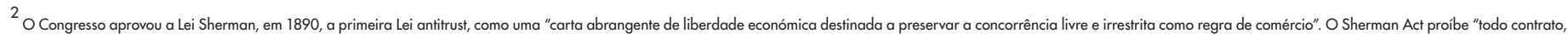

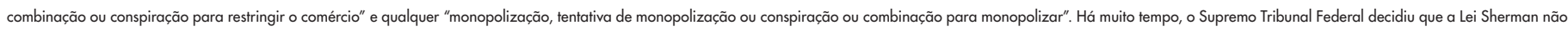
proíbe todas as restrições ao comércio, apenas aquelas que não são razoáveis. O Sherman Act impõe penalidades criminais até USD100 milhões para uma empresa e USD 1 milhão para um indivíduo, com uma pena até 10 anos de prisão 3 Vide, 15 Anos da Reforma Fiscal de 1988/89 (2005), Jornadas de Homenagem ao Professor Doutor Pitta e Cunha, AFP/IDEFF (orgs.), Coimbra.

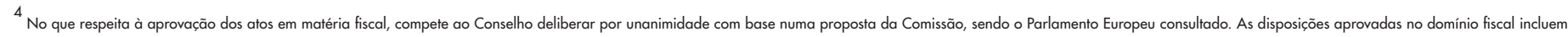

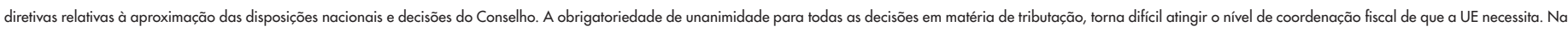
verdade, a Comissão apresentou no passado propostas para introduzir a votação por maioria qualificada em certos domínios, mas essas propostas foram rejeitadas pelos Estados-Membros.
} 
- ganham elevada relevância os poderes tributários constitucionais dos Estados e especial importância as matérias relativas à harmonização fiscal da tributação direta e indireta e o combate à evasão, elisão e fraude fiscal (Pereira, 2004: 60). - dilema da soberania ou sovereignty esteve e estará presente ao longo do processo de integração europeia, pois assume um papel e uma atualidade central na permanente dialética concorrencial entre a UE e os seus Estados-Membros e entre estes (Mclure, 2001). Contudo, ao longo destes 50 anos, o radicalismo da defesa soberana de diversos poderes e atribuições, jamais atingiu a que se manifesta sobre a soberania fiscal, que é uma matéria que se tem mantido políitica e juridicamente afastada de qualquer cedência ou partilha. Na verdade, esta histórica atribuição de soberania, colide com os fundamentos e objetivos que estiveram na essência da criação da UE, nomeadamente, a criação do mercado único e as quatro liberdades consagradas nos Tratados, pois pressupõe uma limitação ao amago do princípio do consentimento popular ${ }^{5}$.

Na verdade, há neste contexto europeu, uma clara e evidente contestação doutrinal a certas posições erráticas do Tribunal de Justiça ${ }^{6}$, que muitas das vezes vai longe de mais, assumindo posições políticas que não the estão atribuídas e que aparecem como assunção de posições políticas, "pondo em causa a soberania fiscal dos Estados" (Ribeiro, 2019: 22).

Neste sentido, pretendemos analisar essa soberania financeira e fiscal e até que ponto a concorrência fiscal prejudicial ou negativa, tem ou não o efeito de colidir e afastar mais as pretensões da UE de poder almejar um estatuto jurídico de harmonização fiscal tal qual o Tratado de Lisboa consagra.

Pretendemos, com rigor e fundamentação cientifica e empírica, analisar os efeitos da integração fiscal nos poderes soberanos financeiros do EstadosMembros, incidindo, sobre a tributação direta das sociedades comerciais, onde em nome de uma política de harmonização fiscal positiva Musgrave, 2006: 180), a comitology, quer a jurisprudência do Tribunal de Justiça da EU quanto à harmonização fiscal negativa (Cédelle, 2015: 2), têm tentado em vão ultrapassar este último reduto dessas atribuições constitucionais nacionais e respetivos poderes financeiros nacionais ${ }^{7}$.

No seio da UE, prevalece um quadro jurídico onde as disposições fiscais - artigos
110. a 113. (TFUE), sobre a harmonização da legislação em matéria de impostos sobre o volume de negócios, impostos especiais de consumo e a outros impostos indiretos, acoplado de um capítulo atinente à aproximação das disposições legislativas - artigos 114. a 118. (TFUE), que abrange os impostos com efeito indireto no estabelecimento do mercado interno e disposições relevantes para a política fiscal, referentes à livre circulação de pessoas, de serviços e de capitais - artigos 45. a 66. (TFUE), ao ambiente - artigos 191. e 192. (TFUE) e à concorrência - artigos 107. a 109. do (TFUE). Em matéria fiscal poderá haver a possibilidade de estabelecimento de uma cooperação reforçada - artigos $326 .^{\circ}$ a $334 .^{\circ}$ do (TFUE).

A soberania em geral e a soberania fiscal em particular, é uma matéria cuja relevância e atualidade na UE levam até com bastante frequência ao extremar de posições políticas por parte dos Estados-Membros (EM), que se mostram inflexíveis em abdicar dessas atribuições e prerrogativas.

Nesse sentido, a regra da unanimidade existente nesta matéria no TFUE, que se tem mantido inalterada para além de muitas convenções e acordos bilaterais, são a prova e a demonstração da inequívoca vontade dos Estados-Membros da UE de quererem manter e defender o seu estatuto de soberania natural quanto seus sistemas fiscais. Contudo, concordamos que o multilateralismo deveria ser a chave de desbloqueio de um sem fim de questões e a ponte do atual projeto de Base Erosion Profit Shifiting (BEPS) para uma governação global institucionalizada (Dourado, 2018: 12).

Ora, esta tendência tem vindo a afirmar-se gradual e paulatinamente no seio da União Europeia, apesar de esta ainda não deter poderes para lançar impostos diretos nos termos dos Tratados por via da aprovação de Diretivas que harmonizem as leis nacionais que dizem diretamente respeito ao funcionamento do Mercado único, embora respeitando a regra da unanimidade, como aconteceu com a harmonização das bases tributárias no âmbito dos impostos indiretos e se esperar que o mesmo aconteça relativamente à tributação das sociedades. Nesta matéria, concordamos com Ribeiro (2019: 25), quando na esteira de Douma e Alexy, defende a manutenção da atual soberania fiscal, que há luz dos princípios de Direito Europeu, sugere "um critério de concordância prática".

${ }^{5}$ Com maior enfâse a partir da Magna Carta de 1215.

${ }^{6}$ Acórdão Schumacker, de 14 de fevereiro de 1995, processo C-279/93 e Acórdão Manninem, de 7 de setembro de 2004, processo C-319/02, n. 19.

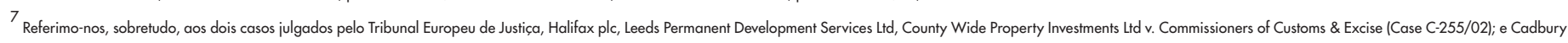
Schweppes plc, Cadbury Schweppes Overseas Ltd v. Commissioners of Inland Revenue (Case C-196/04). 


\section{A soberania fiscal}

É reconhecido pela Doutrina que a delimitação do conceito de soberania na Teoria do Estado não se apresenta de fácil recorte, porque apesar de ser usado quotidianamente, ele projeta um vasto conjunto de dimensões e teorias que historicamente the forram associadas, desde Jean Bodin, e a sua "potestas a legibus soluta", até a Thomas Hobbes e à sua liberdade absoluta de ação monárquica, chegando à constituição dos Estados democráticos e Constitucionais modernos, onde a soberania ganha esporas de indivisibilidade e inalienabilidade em nome do povo que a detém e dela usufrui nos termos das Constituições e do Direito Internacional Público (Saldanha Sanches, 2012: 57).

Quando pretendemos recortar com rigor e precisão o conceito de soberania fiscal (Pires, 2019: 21), como poder supremo do poder de tributar do Estado, este traduzse na atribuição e competência, para poder criar, modificar ou extinguir tributos nos termos e nos limites que decorrem diretamente do texto constitucional (Nabais, 2008: 11)

Como sublinha (Pires, 2019: 23), "O factor de integração económica e as obrigações decorrentes desta integração, nomeadamente no que toca ao controlo das contas públicas (controlo do déficit público) e nas transformações implicadas nas estruturas fiscais daqueles que aderem, resultam, inevitavelmente, num condicionamento da liberdade de organizar e gerir efetivamente o sistema fiscal. Com os fenómenos de integração aparenta-se a permanência de uma soberania fiscal, sendo que a verdade é estar fortemente enfraquecida a soberania fiscal que sobeja".

De facto, no mundo globalizado em que vivemos, é muito difícil ao Estado poder manter a sua soberania fiscal original intocada, pois ela tende a esvaziar-se em razão de múltiplos fatores nacionais e internacionais que a envolvem e limitam. Por outro lado, no caso europeu, apresentando-se as soberanias fiscais bastante fragmentadas, é paradigmático que o Tratado de Lisboa defina como prioridade a importância das receitas fiscais nacionais no contexto do Semestre Europeu, do Pacto de Estabilidade e Crescimento e do Tratado Orçamental, à luz de níveis de fiscalidade e de esforço fiscal nunca vistos, havendo quem assuma já a existência de um Estado Fiscal.

\subsection{Os limites à soberania fiscal}

Os processos de integração são mecanismos e metodologias que como é reconhecido, normalmente, levam à perda ou à limitação dos poderes soberanos dos Estados. No caso da União Europeia, essa perca direta é ainda mais visível e acentuada, uma vez que pelo menos desde 1993, a construção acelerada do mercado único e de uma União Monetária potenciou exponencialmente esse resultado (Quadros, 2004: 445).

Hoje, com facilidade se pode constatar com total transparência a existência de preços e de taxas de lucro taxados com uma diferença de tratamento fiscal grosseira, o que origina deslocalização de empresas, do investimento privado e do capital humano, potenciando gravemente a concorrência fiscal prejudicial no seio da EU e a degradação das bases de tributação

Ora, perante um cenário de limitação europeia dos instrumentos de gestão da política monetária de cada Estado e da vinculação a certas regras orçamentais, os Estados-Membros vêem-se obrigados a resistir a mudanças nas regras atinentes aos sistemas fiscais, que são o único instrumento de intervenção pública nas suas economias. Por outro lado, os Estados clamam há dezenas de anos por uma política europeia de harmonização fiscal. Neste quadro, a existência de uma política europeia de coordenação das políticas fiscais, tentando pôr fim às medidas prejudiciais casuísticas e meramente nacionais, contribuirá para o fortalecimento de cada uma das soberanias nacionais (Santos, 2012: 256).

Como dissemos, tomando em linha de conta os fenómenos globalizantes e a concorrência fiscal prejudicial, que está na base dos problemas constatados na atual erosão da base tributável, a EU fixando taxas harmonizadas de forma coordenada, "poderá atenuar um dos efeitos da concorrência fiscal entre EM - a fixação de taxas reduzidas - a chamada "race to the bottom" (Marques, 2017: 21). Por outro, é reconhecido pela doutrina mais autorizada, que quer o recurso à parafiscalidade, quer o alargamento das funções do imposto, onde as falhas e as insuficiências dos mercados são graves e elevadas, é ao Estado que compete exercer um papel central e estrutural no equilíbrio das sociedades ${ }^{8}$, ajustando de forma mais próxima e eficaz os respetivos sistemas fiscais às novas realidades económicas globais (Tanzi, 2017, p. 5), face à degradação das bases de tributação tradicionais por via da concorrência fiscal prejudicial (Pires, 2019: 29). Devido aos efeitos negativos que quer a concorrência fiscal prejudicial, quer a mobilidade internacional dos investimentos têm na economia mundial e em cada Estado, onde a mobilidade do capital humano se encontra internacionalizado e cada economia tenta melhorar a sua eficácia fiscal através de uma maior coleta de receitas, tem levado também a que muitos sistemas fiscais se vejam na obrigação de proporcionar vantagens fiscais mais atrativas ao investimento externo (Santos, 2017: 34). Ao mesmo tempo, paradoxalmente, participam na construção de medidas globais mais harmónicas e que estabelecem limites a comportamentos 
que distorçam a economia global através de más práticas, injustiças e falta de integridade entre os diversos sistemas fiscais (Dourado, 2018: 11-44).

Contudo, a degradação das bases de tributação tradicionais é em si mesma um fator potencial de afetar o que tributar, prejudicando os resultados do montante sobre o qual o imposto deveria recair, onde o fenómeno do tax jurisdiction shopping leva a que os Estados vejam fugir da sua jurisdição soberana grandes percentagens de receita, em razão da mobilidade do capital e do trabalho. Nesse sentido, simultaneamente, os Estados veem hoje "a par da diminuição do montante do imposto arrecadado, também a capacidade de cobrar impostos afetada" (Pires, 2019: 31-42).

Numa perspetiva complementar, as alterações introduzidas pela globalização da economia, têm produzido profundas consequências à própria estrutura e organização das receitas fiscais, de tal modo que as empresas fazem hoje uso de técnicas avançadas de planeamento fiscal e planeamento fiscal agressivo ou evasão fiscal, em razão da mobilidade do capital e da introdução de tecnologias de informação comportar e cobrir com facilidade os inerentes fluxos financeiros das sociedades e dos rendimentos em geral ${ }^{9}$.

É perante todas estas circunstâncias e limitações que se compreendem os parcos entendimentos no seio do Conselho Europeu em matéria fiscal e sobretudo quanto a avanços na harmonização fiscal.

Num mercado único que se quer transparente, concorrencial e livre, a harmonização fiscal é um instrumento crucial para eliminar as diferenças discriminatórias e os obstáculos jurídicos à sua concretização e para a realização da União Económica e Monetária, uma vez que os artigos 114. e 115. do TFUE preveem a "aproximação das disposições legislativas, regulamentares e administrativas dos EstadosMembros", que tenham "por objeto" e "incidência direta" no estabelecimento e o funcionamento do mercado interno.

Assim, apesar dos normativos enunciados anteriormente não coincidirem, nem no procedimento, nem no objeto da harmonização lo artigo $114 .^{\circ}$ do TFUE baseia-se num processo legislativo ordinário, excluindo expressamente do seu âmbito de aplicação as disposições fiscais, as relativas à livre circulação das pessoas e as relativas aos direitos e interesses dos trabalhadores), do seu conteúdo poderemos enunciar dois postulados da harmonização fiscal: a progressividade e o respeito pela especificidade dos direitos nacionais. Ou seja, a harmonização fiscal terá de se limitar a todo o tempo às disposições diretamente relacionadas com o estabelecimento e funcionamento do mercado interno e terá de manter o respeito pelos sistemas jurídicos nacionais, com respeito integral e absoluto do princípio da subsidiariedade e proporcionalidade - artigo 5..$^{\circ}$ do TUE. Neste sentido, os Estados-Membros podem manter a sua soberania fiscal intocada, tanto quanto mais e melhor conseguirem resolver localmente e de forma próxima os assuntos relacionados com o seu sistema fiscal ou por via de critérios europeus largos que tratem como grande chapéu os níveis mínimos de tributação.

\section{A concorrência fiscal internacional}

A concorrência fiscal internacional é uma matéria central nas relações económicas internacionais que afeta cada vez mais a atuação de cada Estado de per si, pois as formas internas e externas de atração de investimento e capital estrangeiro em mobilidade (Pires, 2019: 236), exige em cada momento, alterações dos próprios sistemas fiscais para a criação de melhores condições para esse investimento.

Perante os desafios que as necessidades de financiamento dos Estados confrontam os cidadãos, as necessidades públicas de natureza social (Saúde e Segurança Sociall, infraestrutural, organizacional e de qualificações, torna-se obrigatório a adoção de técnicas de planeamento fiscal, minimizando as alterações saturadas das suas cargas fiscais, bem como permite o crescimento da riqueza criada e cada ano e a internacionalização das suas empresas e economias, sem prejudicar as economias de outros Estados.

Nesta matéria, tem-se levantado a questão de equacionar qual o local de tributação das operações realizadas pelos agentes económicos e se pode ou deve existir concorrência fiscal prejudicial entre Estados.

Neste sentido, o fenómeno de concorrência fiscal prejudicial internacional tem vindo a desencadear na UE e no âmbito da OCDE, a adoção de medidas por parte dos Estados para o controlo e extinção das práticas consideradas como prejudiciais, para que a exequibilidade das quatro liberdades fundamentais seja uma realidade ${ }^{10}$

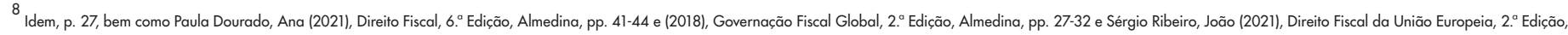
Almedina, p. 20.

9

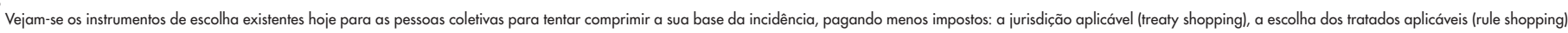
os preços de transferência (transfer pricing), a subcapitalização (thin capitalization) ou a não distribuição de lucros.

${ }^{10}$ Tratado de Lisboa. www.dgeg.gov.pt.
} 


\section{A concorrência fiscal prejudicial}

Quando um Estado se socorre de manobrar as regras fiscais com o propósito de promover a atração de maiores receitas fiscais em face do investimento externo em detrimento de outros Estados, em virtude da alteração de pressupostos como sejam o modo de tributação ou em razão do enquadramento administrativo, contabilístico ou de redução de certos impostos "para deslocar a base de tributação para o espaço fiscal em que tal ocorra" (Pires, 2019: 235), estamos perante uma prática de concorrência fiscal prejudicial.

○ fenómeno da concorrência prejudicial releva para o entendimento que é da responsabilidade de cada Estado, verificar "em que condição é realizada a tributação das operações efetuadas pelas empresas - a tributação pode ocorrer ou na origem ou no destino dos bens e/ou serviços" ${ }^{11}$, considerando-se para Portugal, os países que integram a Portaria n. 150/2004, de 13 de fevereiro, de onde resulta a existência de um regime favorável para as empresas que se sedearem ou que transponham os seus lucros.

Nessa sequência, e tendo presente diversas ações que visam contribuir para a luta contra a fraude e evasão fiscal, englobando as relações com Estados terceiros, em virtude do cumprimento das obrigações fiscais, da implementação de ações concretas para reforçar a cooperação administrativa e o desenvolvimento económico, políitico e fiscal no âmbito da boa governança, a União Europeia impele os Estados a implementá-las, no sentido de que os seus contribuintes possam usufruir de uma real redução de custos fiscais e bem assim da criação de sistemas fiscais mais eficazes por via da troca de informação automática e de facilitar o tratamento dos riscos transfronteiriços, estimulando-se o reforço para a cooperação entre Estados ${ }^{12}$.

Assim, cada Estado pode implementar ações contra a prática prejudicial, em virtude da soberania fiscal independente, fazendo uso de ferramentas como seja o planeamento fiscal ou adoção de acordos que visem eliminar a dupla tributação entre Estados e consequentemente os constrangimentos negativos refletidos nas economias globais de hoje.

Quando um Estado, reescreve a forma de tributação, altera a favor dos sujeitos passivos dos impostos os seus pressupostos objetivos e subjetivos ou as taxas e as deduções à coleta, as normas de contabilidade, diminuem as exigências bancárias ou administrativas, habitualmente, desse modo aumentam as receitas fiscais.

No entanto, as medidas de planeamento fiscal, realçam formas prejudiciais de recolha das receitas fiscais de um outro Estado, uma vez que quer os contribuintes, quer as empresas, irão tendencialmente optar por um território em que o valor de impostos seja mais reduzido, transpondo dessa forma os seus recursos produtivos e financeiros, como aliás se verificou no caso de algumas empresas portuguesas que optaram por sistemas fiscais como o holandês ou maltês, contribuindo esse facto para a redução das finanças publicas portuguesas.

Fatores como a globalização, a intensidade da internacionalização das empresas, a integração dos recursos financeiros nos variados mercados, a digitalização, e bem assim a mundialização da economia, contribuem para que os diversos atores - Estados, Empresas e Contribuintes, concorram para construir as melhores condições tributárias com vista a garantir e atrair as suas e novas bases de tributação, contribuindo por essa via para a criação de paraísos fiscais e bem assim de regimes fiscais prejudiciais.

Assim, qual a unidade uniformadora de caraterização da existência de concorrência fiscal prejudicial?

A designação de tax degradation (degradação fiscall), durante muito tempo resultou no termo harnmfull tax practices (concorrência fiscal prejudicial), no entanto, nos dias de hoje, dirige-se a todas as formas de tributação e de acordo com António Carlos Santos ${ }^{13}$, existem três tipologias de classificação:

a) A concorrência horizontal, vertical ou oblíqua, em virtude dos níveis de autonomia e hierarquia estadual;

b) A concorrência fiscal interior e exterior, nos termos de uma certa pressão para que os cidadãos mantenham a sua residência habitual ou visando a captação de novas ou mais alargadas bases de tributação;

c) A concorrência fiscal ofensiva e defensiva, em virtude de atrair novos fatores de produção e tributação ou para dissuadir a saída das bases de tributação exstentes.

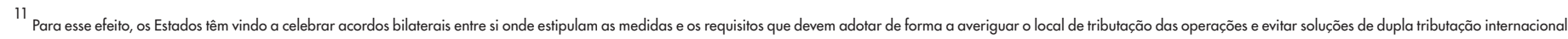
Cfr. Devereux, Michael P. e Lorety, Simon (2009), "Qu'est-ce que la concurrance fiscale et comment se manifest-t-elle?", Statégies Fiscales des Etats et des Entrepises: Souveraineté et concurrance, Paris, PUF, pp. 16-31.

12 Portugal adotou as seguintes medidas de controlo concorrencial fiscal prejudicial:

a) Medidas antiabuso geral e específicas no CIRC;

b) A cláusula geral Anti-abuso - LGT Artigo $38, N^{\circ}{ }^{\circ}$;

c) Preços de transferência- CIRC Artigo $63^{\circ}$.

d) Pagamentos a entidades não residentes sujeitas a um regime fiscal privilegiado - CIRC, Artigo 65.;

e) Imputação de lucros de sociedades não residentes sujeitas a um regime fiscal privilegiado - CIRC Artigo $66^{\circ}$
} 
A concorrência fiscal ativa, passiva ou por imitação é igualmente alvo de distinção por parte da doutrina. Assim, a concorrência fiscal ativa pressupõe que um Estado pretende tornar-se num local mais atrativo para $\circ$ investimento interno e externo em razão da sua competitividade fiscal. $\bigcirc$ desenho da sua competitividade fiscal pode residir em políticas fiscais agressivas, traduzindo-se numa concorrência fiscal ofensiva ou de posição defensiva, de reação apenas na presença de arranjos fiscais agressivos de outros Estados, criando uma política interna de concorrência fiscal defensiva. Já a concorrência fiscal passiva, resulta da existência de diversos sistemas fiscais, sendo que estes são o reflexo das conjunturas social e económica, de diversos patamares de desenvolvimento e dos variados enquadramentos políticos nacionais ou de organização económica e judicial.

A doutrina fiscalista, defende neste âmbito uma teoria económica designada por "Prisoner's Dilemma", para classificar a ação de certos países aquando da assunção de determinado desenho de política fiscal ou na defesa de efeitos nocivos originários em politicas de concorrência fiscal ativa externas; a) adotando ações semelhantes para evitar colocar em risco a sua competitividade fiscal internacional; b) não adotando qualquer medida fiscal combativa ou; c) criando medidas fiscais construídas diretamente para fazer face às políticas fiscais de outros estados que impulsionem as suas políticas ativas de concorrência fiscal.

Face ao exposto, a UE e a OCDE, enquanto instituições de supervisão neste âmbito, têm vindo a realizar diversos estudos mas sem alcance efetivo no que concerne à definição objetiva do conceito jurídico de concorrência fiscal prejudicial e bem assim da sua delimitação ou regulamentação geral ${ }^{14}$. Tanto mais assim é, que a partir das diversas formas e elementos de tributação, cada Estado pode a partir do património, da despesa, do rendimento, do trabalho ou lucro e do capital, projetar arranjos legislativos que reforcem cada uma das formas de concorrência fiscal, que deverão ter presente diversos aspetos de proximidade e igualdade quanto a situações condicionantes de investimento, tendo em conta as circunstâncias e especificidades históricas, visando alcançar um equilibrio, balizado no panorama Português pelos limites constitucionais dos princípios da equidade e igualdade fiscal.

Para a defesa dos variados princípios e critérios, o certo é que os Estados pretendem desenvolver esta matéria com equilíbrio, impondo limites à inexistência de impostos, a estabilidade da sua fonte de rendimentos, a isenção de rendimentos externos ou de benefícios fiscais provenientes de outros regimes fiscais externos.

\subsection{As suas motivações e os seus sujeitos}

Os diversos tipos de tributação sobre o rendimento, nomeadamente o imposto sobre o trabalho, o capital, o património, o lucro e a despesa, enquadram situações de potencial concorrência fiscal prejudicial, incluindo, igualmente, certas especificidades da tributação que passam pela sujeição, benefícios fiscais e taxas, entre outros.

No entanto, para a existência jurídica de concorrência fiscal ${ }^{15}$, é necessário a verificação de certos pressupostos como sejam a igualdade, bem como, de situações cuja proximidade estão ligadas a restrições que condicionam o investimento e que devem ser sempre tidas em conta, independentemente do passado, presente ou futuro ${ }^{16}$

Por exemplo, estamos perante o planeamento fiscal agressivo que tenta obter e manter investimento utilizando mecanismos de evasão fiscal legal ou nos seus limites ${ }^{17}$. Como é consabido, nos dias de hoje, é viável convocar diversos mecanismos que beneficiam das práticas fiscais concorrenciais e que, por seu turno, estão ligados à tributação mais vantajosa, nomeadamente, as sociedades holdings, centros de coordenação, off shore, e bem assim, sociedades e fundos imobiliários (Andrade, 2001: 209).

Em relação aos paraísos fiscais e à sua fiscalidade, verificam-se diversas situações: i) ausência de impostos em face da tributação irrelevante existente aplicável, ou em face da determinação limitada da fonte de rendimentos sujeitos, pese embora a tributação não seja tão relevante; ii) rendimentos originários do exterior excluídos de qualquer tributação; iii) regimes com menos impostos face os rendimentos em relação ao que existiria no país de origem ou; iv) regime de confidencialidade em que o segredo releva para a não tributação efetiva, uma vez que existe a não identificação subjetiva dos sujeitos.

Com este enquadramento jurídico-económico e penal, recaem sobre os regimes fiscais prejudiciais, circunstâncias jurídicas em que as taxas efetivas sobre os rendimentos são demasiado baixas ou inexistentes e em que o enquadramento

\footnotetext{
${ }^{13}$ Santos, António Carlos "Concorrência Fiscal e Competitividade - A Never Ending Story", Ciência e Técnica Fiscal, n. 0 424, pp. 8-10.

14 Palma, Clotilde Celorico (2010), "O Código de Conduta da Fiscalidade das Empresas e a Boa Governança Fiscal", Revista do Curso de Mestrado da UFC, vol. 30 n. 2, jul/dez., pp. $211-225$, in www.periodicos.ufc.br

15 Para esta questão são colocadas várias questões, questões estas que deveriam ser respondidas. Quanto à soberania dos Estados quais os limites que devem ter, já que a fiscalidade é um dos protestos com mais relevância?

${ }^{16}$ Solidez económica e social, risco de nacionalizações, privações, justiça, leis laborais, probabilidade de repatriamento de capital e de rendimentos, entre outros fatores.

17 A concorrência fiscal resulta, sobretudo, do aparecimento de paraísos fiscais (tax heavens), e de regimes fiscais preferenciais prejudicais (harmful preferential tax regimes).
} 
tributário não se estende a atividades locais, isto é, circunscreve o seu âmbito de aplicação a não residentes ou então não autoriza transações em divisa nacional, implementando uma ausência de transparência na administração e a não troca efetiva de informações com outros Estados.

A par das questões fiscais, são ainda considerados outros aspetos atrativos fiscalmente, como sejam as confidencialidades bancárias ou comerciais, a ausência de controlo por parte das entidades monetárias e cambiais, a estabilidade económica e política, legislação comercial com disposições liberais, existência de conselheiros especializados, designadamente de contabilistas e de advogados $^{18}$. Outros aspetos a ter em consideração são a existência de tratados fiscais ou a auto identificação em certo Estado ser um paraíso fiscal. Estes regimes somam outros aspetos atrativos, como seja a falta de transparência das normas legais e administrativas, e a ausência de tributação sobre variadas atividades, cujos rendimentos são de natureza meramente passiva.

Podem ainda ser adicionados factos como a falta de adesão aos princípios internacionais dos preços de transferência, a isenção de rendimentos com origem no estrangeiro, total acesso a uma rede de tratados fiscais, promoção destes regimes em razão da sua transmissibilidade de minimização fiscal e pelo facto de impulsionarem operações ou organizações transmissoras de uma perspetiva ativa fiscal, embora não exista qualquer atividade ${ }^{19}$

Numa abordagem imaginária, na circunstância de não existirem práticas fiscais prejudiciais e apenas existir concorrência fiscal benéfica ${ }^{20}$, as suas vantagens passariam por existir tributações mais baixas, onde a eficiência económica seria concretizada num patamar mas significativo de desenvolvimento, onde a receita tributária seria mais elevada e haveria uma melhoria dos serviços coletivos, como resultado, haveria uma clara melhoria do nível de vida (Pires, 2011: 49). No entanto, ao fixar-se um equilíbrio entre a tributação que é suportada e as despesas públicas que com estas são executadas a favor da sociedade, o seu enquadramento não levará a que os serviços realizados pelo Estado continuem caso se verifique um decréscimo das receitas, mesmo apelando-se a mais produtividade das empresas e das pessoas. Ou seja, em relação ao nível da fiscalidade e ao nível da despesa pública que existe, não deveria existir um maior equilíbrio? (Silva, 2019).

\subsection{Os seus obstáculos, relevância e status quo}

Já foi assumido por parte da União Europeia que a concorrência fiscal é benéfica para os contribuintes permitindo uma redução da despesa pública ${ }^{21}$, ou seja, um certo grau de concorrência fiscal na UE pode ser inevitável, podendo mesmo contribuir para diminuir a pressão global ${ }^{22}$.

Assim sendo, pergunta-se, não deveriam as finanças públicas serem reconhecidas como um todo, integrando toda a despesa e receita nacional, além de analisar a existência de lucro ou prejuízo de empresas e pessoas no âmbito europeu?

Ao haver liberdade de decisão, os agentes económicos não devem sofrer limitações pela sua escolha (Dourado, 2018: 27-32). A ausência de concorrência no mercado pode resultar num aumento descontrolado de preços, através da ação dos seus intervenientes ou por imposição de outros fatores, circunstância que pode ser verificada com os níveis de tributação. A concorrência poderá levar a uma eficiência interestadual refletindo-se numa menor carga fiscal, o que se traduz num aumento do crescimento económico. De realçar que em relação ao aumento fiscal, este não é por si o fator de maior relevância e único em face das medidas tomadas no que diz respeito à localização de bases tributáveis.

Em relação à evasão e planeamento fiscal, cumpre realizar a diferença entre estes, sendo que o último é legal e legitimo. A OCDE, em 1987, afirmava que, "The scope of what is considered as tax avoidance may vary from country to country depending not only on the for a particular scheme may take, but also on attitudes of government, parliament, public opinion and the courts, which may themselves

\footnotetext{
${ }^{18}$ Isto não quer dizer que não existam critérios especiais consoante os tipos de atração. Deste modo, a regulação fiscal para as sociedades holding não é a mesma para as trusts.

${ }^{19}$ Ver OCDE 1998, Harmful Tax Competition. Paris, pág. 19 e ss.

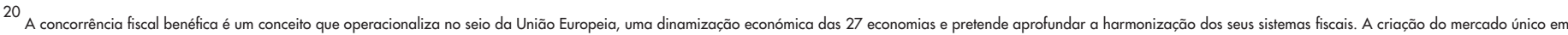

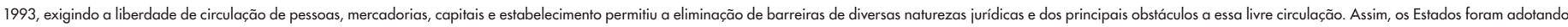
um vasto conjunto de mecanismo de correção e aproximação, que potenciaram a sua própria competitividade, pois os investidores dirigirem-se, normalmente, a Estados mais desenvolvimento, mais ricos e mais populosos.

${ }^{21}$ COM (97), Rumo a uma coordenação em matéria fiscal na União Europeia, de 1.10.1997

22 COM (2001), A política fiscal da União Europeia: prioridades para os próximos anos, de 25.05.2201.

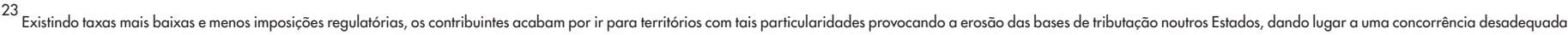
No entanto, esta argumentação parte do princípio de que há perdas para a concorrência global, o que não é comprovado.
} 
change within one country and over time. However, this does not imply that OECD government are not generally in agreement on what constitutes the range of tax avoidance they wish to combat or that they have problems in identifying it" IOCDE, 1987: 16-17).

Entre os diversos aspetos a favor da concorrência fiscal, verificam-se, igualmente, alguns constrangimentos, como sejam: i) a diminuição da soberania fiscal, uma vez que esta atividade está dependente do que se passa nos outros Estados; ii) a não neutralidade, pela influência exclusiva ou primacial do fator fiscal, originando a deslocação da atividade financeira e dos serviços, pode levar a que haja uma situação de risco para a livre concorrência no comércio e no investimento; iii) a redução excessiva das bases de tributação e decréscimo das receitas, sendo que estas são essenciais para os países desenvolvidos cujo nível da despesa e a criação de dificuldades para a redução ou eliminação do défice público que é crucial; iv) a troca do trabalho pelo capital, verificando-se questões ao nível do desemprego refletidas numa economia nacional menos competitiva; v) elevada carga fiscal sobre fatores produtivos que tem menos mobilidade ou que são instáveis, por exemplo o trabalho dependente; vil questões de tributação afetando a redistribuição do rendimento e ainda o aumento de novas vias para a fraude e evasão fiscal (OCDE, 1998: 8-13).

Das questões acima enumeradas, apenas alguns estados acolhem as mesmas, bem como a questão da diminuição ou eliminação de alguns impostos, pois tal fato iria originar o aumento de outros ${ }^{23}$. Em particular, iria verificar-se perda de receitas fiscais, ou seja, erosão da base tributável que releva para as bases de tributação, constituindo uma política begger-my-neighbour (Pinto, 2002: 47).

Decerto, esta políitica viria a beneficiar técnicas de redução de impostos por via da evasão e da fraude fiscal, introduzindo impactos nas sociedades e constrangimentos ao princípio da igualdade. Ao ampliar uma redução da tributação, constitui-se uma redução das receitas fiscais e, se o Estado consolidar uma roła de maior produtividade e riqueza, haverá, pois, uma menor tributação do capital e uma maior tributação referente ao trabalho ${ }^{24}$, imoveis e consumo ${ }^{25}$, o que penaliza, sobretudo, as classes médias.

A par do exposto, somam-se mais constrangimentos, como sejam o efeito da redução sobre dos serviços do Estado com reflexo na redução de receitas em países que se encontram em desenvolvimento ${ }^{26}$ e depois o caminho para o abismo (race to the bottom), e assim consecutivamente, tornando-se num círculo vicioso. Desta forma a equidade e a eficiência económica entre nações seriam afetadas. Desta forma, o espaço fiscal é alvo de danos e não consegue regulamentar o seu sistema conforme se pretenderia, sendo que é afetado pela tributação de outros espaços fiscais. Deste modo, existem restrições ao nível da sua soberania tributária.

Por outro lado, através da erosão da base tributável e da diminuição da receita, desaparecem certos bens públicos com efeitos no Estado Social e no equilíbrio económico e social nas sociedades modernas, aprofundando as desigualdades e a pobreza.

\section{A Harmonização Fiscal - realidade ou mito?}

Fabio Wasserfallen ${ }^{27}$, considera que de todos os aspetos realçados sobre o processo de harmonização fiscal na União Europeia, a mais importante é se existe necessidade de complementar o nível atual de integração económica, por via de uma maior integração politica, designadamente, através de uma transferência ainda que reduzida e limitada de poderes de âmbito nacional para um âmbito mais concentrado europeu e adianta para a necessidade de substituir a regra da unanimidade para a regra da maioria qualificada, tido igualmente, por muitos autores a pedra angular que tornará mais fácil o caminho para a harmonização fiscal (Pollack, 2003: 56). Esta argumentação colhe para a centralidade da política fiscal ao nível europeu enquanto fator essencial para a sustentabilidade da mesma, fundamentando-se não apenas por ser um mecanismo bastante eficaz no combate aos choques económicos a que mesma está sujeita, mas ainda, porque historicamente, nunca se verificou uma união monetária que tivesse sucesso sem que o passo da harmonização fiscal fosse dado (De Grauwe, 2006: 711-730).

Pese embora estes factos e de acordo com o anteriormente referido, ainda existirem áreas políticas (segurança social, educação, defesa, impostos) que estão diretamente relacionadas com a soberania de um país e que se balizam na esfera nacional, não tendo sido transposta para o âmbito supranacional como é o caso de uma fatia importante da política económica, financeira e monetária da União

\footnotetext{
${ }^{24}$ Designadamente o trabalho não qualificado uma vez que este tem mais facilidades de deslocação.

${ }^{25}$ Aplicável ao comércio tradicional, ou ao comércio eletrónico indireto. Porém, existem dificuldades de tributação no comércio eletrónico direto ou on-line.

${ }^{26}$ Não se teve em conta a obtenção de receitas através da criação de empregos

${ }^{27}$ Wasserfallen, Fabio (2014), "Political and Economic Integration in the UE: The case of Failed Tax Harmonization", JCMS: Journal of Common Market Studies, Vol 52, pp. 420-435.
} 
Europeia conforme o Pacto de Estabilidade e Crescimento e o Semestre Europeu. Para alcançar o desígnio de um Mercado único sustentável e eficaz, é necessário a promoção de políticas fiscais supranacionais, ou seja, políticas desenhadas ao nível central e que atravessem o âmbito nacional.

certo é que a par desta evidência a legislação atual da União Europeia falha por falta de definição jurídica de limites fiscais ao nível central e que possibilitem aos organismos da União Europeia a legitimidade para implementação de uma política fiscal europeia. Ao invés, tem-se verificado a falta de produção de legislação fiscal que contribua para uma maior harmonização fiscal, sendo que desde 2003, poucos ou nenhuns são os progressos nesta área (Ribeiro, 2021: 22-25)

facto é que a integração de âmbito política significa a cedência de soberania e o esvaziar do controlo nacional em determinadas temáticas centrais de governação de um país, ao contrário da integração económica, designadamente no âmbito fiscal e social, com o seu expoente máximo na redistribuição do rendimento (Niazi \& Krever, 2015: 455-4701.

Um dos aspetos mais relevantes da histórica da União Europeia foi a introdução da moeda única. $\bigcirc$ Euro trouxe consigo a perda do controlo da política monetária por parte dos Estados-Membros, que aderiram à UE e que a transpuseram para a esfera do Banco Central Europeu. Ao contrário dos vários alargamentos, que introduziram diversos constrangimentos à construção de uma política fiscal europeia, a moeda única ampliou as vantagens na centralidade das políticas a nível da União Europeia, o que coloca mais perto a questão da harmonização fiscal $^{28}$, no entanto, a situação atual denota que o próximo passo logico impõe a cedência do controlo da política nacional por parte dos órgãos nacionais perante os órgãos supranacionais, o que no desenho atual da UE é de momento intangível. No entanto, autores como Niazi, realçam que uma ação de concertação de poderes semelhante ao processo de Schengen, será o único caminho para eliminar a espera pelos repetidos vetos de âmbito europeu e bem assim a forma da promoção da harmonização fiscal no seio da UE, ainda que se admita que tal posso desenvolver-se, mesmo e apenas numa primeira fase ao nível da zona euro (Ribeiro, 2021: 21-25).

\subsection{A Harmonização fiscal e as sociedades}

José Casalta Nabais ${ }^{29}$ defende que a harmonização fiscal positiva ou legislativa pode ser considerada como aquela que é transcrita por via de regulamentos, recomendações, diretivas, decisões ou convenções.

Refere ainda Casalta Nabais ${ }^{30}$, que a harmonização fiscal tem como objetivo, ser o caminho face à eliminação de constrangimentos ao nível da livre circulação de mercadorias, pessoas, serviços e capitais. Neste enquadramento, depreende-se que os Tratados que instituíram as Comunidades, numa primeira fase de integração europeia, apenas tenham tido em conta necessária a harmonização dos impostos indiretos para o objetivo da neutralidade fiscal faz transações, e por esse motivo, essencial face à remoção de constrangimentos à livre circulação de bens no âmbito do espaço europeu (Pereira, 2004: 193).

Sendo que, apesar de alguns obstáculos, o Imposto sobre o Valor Acrescentado (IVA), foi o que atingiu um patamar de harmonização expressiva quando analisado em comparação com a tributação direta.

Considerando a premissa anteriormente explicitada, os Estados-Membros, assumem a harmonização do IVA como um imperativo, "porque o IVA é recurso próprio comunitário, porque um dos objetos de incidência são as importações de países terceiros (de valor aduaneiro comum), porque a fase da união aduaneira era a primeira e era incontestável no processo de integração europeia" (Dourado, 2021: 26)

défice da harmonização da tributação indireta infere diretamente com os obstáculos da integração económica e bem assim a interpretação do TJUE sobre a fiscalidade direta, bem como, a circunstância dos Estados-Membros alocarem principalmente a sua tributação direta aos seus objetivos de política fiscal (Pereira, 2004: 1981.

A fiscalidade direta, em particular nas empresas, enuncia-se no âmbito da integração económica, designadamente na prossecução do ideal da construção e pleno funcionamento do mercado comum e de concretização as liberdades versadas nos Tratados ${ }^{31}$, assinalando-se a produção de diversos relatórios, programas, estudos e propostas sobre a matéria.

processo de harmonização da tributação sobre as sociedades, é um dossier

\section{${ }^{28}$ Wass} ao nível da criação de um imposto comum a nível da zona euro, um imposto europeu se assim o quisermos designar.

${ }^{29}$ Nabais, José Casalta (2015), Introdução ao Direito Fiscal das Empresas, 2. edição, Coimbra, Almedina, p. 96.

30 Idem, p. 97.

${ }^{31}$ Livre circulação de mercadorias, de pessoas, de serviços e de capitais. 
muito lento e prolongando ao longo dos tempos das Comunidades, 1951 até 2021.

Contudo, há que sublinhar que apesar do atual projeto BEPS enquadrar o pensamento sobre a tributação das sociedades e de muito influenciar os pensamentos fiscais nacionais para uma boa governação fiscal, está muito longe de obter resultados práticos, sobretudo em face da limitada coragem de mudança de paradigma e de rutura, pois as questões da transparência fiscal e o combate ao planeamento fiscal agressivo exigem medidas mais veementes e eficazes de harmonização fiscal (Brauner, 2014: 14-39).

No entanto, no ano de 2003, o Conselho adotou a Diretiva 2003/123 CE ${ }^{32}$, que altera a Diretiva Sociedades Mães-Afiliadas. A expressão reside no âmbito de aplicação face a outras entidades, passando a aplicar-se à Sociedade Europeia e Sociedade Cooperativa Europeia, passando de 25\% para 10\%, o limar necessário de participação de empresas para que sejam aplicados os benefícios possíveis, e ainda contribuir para melhorar os mecanismos no âmbito da eliminação da dupla tributação ${ }^{33}$. A Diretiva 90/435/CEE foi revogada em 2011, pela Diretiva 2011/96/UE do Conselho de 30 de novembro de $2011^{34}$, que consequentemente foi alterada pela Diretiva 2014/86/EU do Conselho, de 8 de julho de 2014 e pela Diretiva (EU) 2015/121 do Conselho, de 27 de janeiro de 2015, que introduziram inovações em matéria de combate à dupla tributação e a introdução de uma clausula geral antiabuso.

A Diretiva 2005/19/CE $E^{35}$, aprovada em 2005, em 27 de fevereiro pelo Conselho, altera a Diretiva Fusões e Cisões que além do alargamento a outras entidades, inclui também as operações de cisão parcial.

A Diretiva 2005/19/CE bem como as suas alterações, foram revogadas em 2009, sucedendo desse facto que o regime fiscal comum aplicável a fusões, cisões, cisões parciais, entradas de ativos e permutas de ações entre sociedades de EM distintos e à transferência da sede de uma SE ou de uma SCE de um EM para outro, a estar vertido na Diretiva 2009/133/CE, do Conselho, de 19 de outubro de $2009^{36}$

A Diretiva 2004/56/CE do Conselho de 21 de abril ${ }^{37}$, que altera a Diretiva 77/799/CEE, publica o regime de assistência mútua. $\bigcirc$ aumento da cooperação administrativa no âmbito da União é objeto de diversas menções e crescentemente impulsionado, enquanto forma de deteção e neutralização mais eficaz face a desvios, esquemas fiscais fraudulentos e casos de não tributação ${ }^{38}$. A boa governação fiscal e a necessidade de cooperação de matéria fiscal, ganha expressão através das questões resultantes da crise financeira e económica, das questões de fraude e evasão, branqueamento de capitais e terrorismo, globalização, evolução tecnológica e a crescente integração dos mercados ${ }^{39}$ Nesta sequência e aprovada a Diretiva 2011/16/UE do Conselho, de 15 de fevereiro $^{40}$ (DCA 1), no âmbito da cooperação administrativa face ao domínio da fiscalidade e que revoga a Diretiva 77/799/CEE.

A 16 de março de 2010, o Conselho adotou a Diretiva 2010/24/UE, relativa à assistência mútua ao nível da cobrança de créditos referentes a impostos, direitos e outras medidas ${ }^{41}$, que revoga a Diretiva 2008/55/CE do Conselho de 26 de maio de 2008, com efeitos a partir de 1 de janeiro de 2012.

Em 2011, a Comissão Europeia, publicou uma proposta de Diretiva ${ }^{42}$, que revoga a Diretiva dos Juros e Royalties de 2003, com o objetivo de alargar o âmbito das sociedades às quais a Diretiva se aplicava, reduzir o âmbito das empresas associadas e reduzindo o limite de participação direta de 25\% para $10 \%$ de participação direta ou indireta no capital social.

A Comissão dá conhecimento da sua insistência na concretização de tal propósito, veja-se as diversas comunicações ${ }^{43}$, realçando as vantagens desta introdução, criando em 2004 um grupo de trabalho ${ }^{44}$, face à introdução da "matéria coletável comum consolidada do imposto sobre as sociedades" (MCCCIS), sendo que não se verificaram nenhumas ações objetivas neste âmbito, verificando-se a resistência dos EM em perder a sua soberania fiscal em sede de tributação direta.

\section{Conclusões}

No âmbito da União Europeia várias foram as perspetivas e tentativas, como seja: a tributação pelo Estado Origem ("Home State Taxation"); tributação de base comum (consolidada) ("Common" (Consolidated) Base Taxation); imposto europeu sobre os rendimentos das empresas ("European Corporate Income Tax"); e uma

\footnotetext{
32 JO L de 13/01/2004.

33 Iniciativas legislativas europeias traduzidas em consequência do estudo da Comissão Europeia "Um estudo analítico da fiscalidade das empresas na Comunidade Europeia" (SEC (2001) 1681).

34 JO L 345 de 29/12/2011.

35 JO L 58 de 04/03/2005.

36 JO L 310 de 25/11/2009.

37 JO L 127 de 21/04/2009
} 
DOl: $10.46294 /$ ulplr-rdulp.siv lab

abordagem mais tradicional com a criação de uma base tributável e de um regime fiscal únicos para as empresas da UE, substituindo os regimes nacionais em vigor. Nesse pressuposto, a opção por uma MCCCIS opcional para as empresas e que se amplificasse entre os EM, foi tida como o meio mais eficaz para a sua aplicação, o que significaria que as empresas beneficiariam de um sistema de balcão central. $\bigcirc$ carater opcional poderia levar a que a MCCCIS se tornasse muito concorrencial, simples e uniforme, tanto quanto possível, em toda a UE ${ }^{45}$. Assim, esta opção por uma matéria coletável comum consolidada do imposto sobre as sociedades, foi tida como uma ferramenta imprescindível a diversos níveis, como sejam o sucesso do mercado interno, o aumento do crescimento e do emprego, o reforço da competitividade das empresas da UE nos mercados globais, na atratividade face ao investimento intracomunitário e estrangeiro, mas o que originou que em 2018 a Comissão tivesse apenas proposto duas Diretivas do Conselho que se destinavam a tributar de forma justa as empresas de serviços digitais e financeiros.

A matéria relativa à erosão da base tributável e a transferência de lucros para países com menor tributação é uma questão que coloca em causa a soberania financeira dos Estados. Por esse facto, esta matéria tem vindo a ser colocada na agenda a nível global, merecendo destaque o trabalho desenvolvido pela
OCDE que se traduziu na apresentação de um Plano de Ação BEPS ${ }^{46}$ em 2013 (Dourado, 2018: 103).

Ao nível da UE é ainda mais expressivo os desafios em matéria de planeamento fiscal, considerando a necessidade de harmonização entre a soberania fiscal dos Estados-Membros, a construção do mercado único para pessoas, mercadorias e capitais e a concorrência fiscal entre países (Dourado, 2018: 12).

Senão vejamos, a proposta de alteração da Diretiva das Sociedades MãesAfiliadas ${ }^{47}$, visando a luta contra as disparidades em matéria de instrumentos financeiros híbridos no âmbito da aplicação da Diretiva, que poderiam contribuir para situações de dupla não tributação e a introdução de uma cláusula geral antiabuso $^{48}$, com o propósito da proteção do seu funcionamento - JO $L 21$ de 28/01/2015.

No que diz respeito à troca automática de informações obrigatórias ao nível da fiscalidade, foi aprovada a Diretiva 2014/107/UE do Conselho, de 9 de dezembro de $2014^{49}$

De referir, igualmente, que quer a alteração ao nível da UE, quer a norma mundial da OCDE, têm na sua origem o trabalho promovido entre o EUA e outros países, onde se incluem os EM, por via de acordos bilaterais ao nível da troca automática de informações para aplicação da Lei de Conformidade Fiscal de Contas

\footnotetext{
38 Veja-se as Comunicações da Comissão COM (2005) 0525; COM (2006) 0823 final, COM (2007) 785 final; e COM (2009) 0201 final.

${ }^{39}$ Veja-se a comunicação da Comissão COM (2009) 0201 final.

40 JO L 64 de 11/03/2011.

41 JO L 84 de 31/03/2010

${ }^{42} \operatorname{COM}(2011) 714$ final.

${ }^{43} \operatorname{COM}(2003) 726$ final; $\operatorname{COM}(2005) 532$ final; $\operatorname{COM}$ (2010) 608 final; COM (2011) 0712; e COM (2011) 0206 final.

44 Grupo de trabalho composto por peritos e partes interessadas dos EM trabalhou entre 2004 e 2008 e prestou assistência técnica à Comissão na elaboração da proposta de 2011.

${ }^{45} \operatorname{COM}(2006) 157$ final.

${ }^{46}$ Disponível em hitp://www.ocde.org/tax/beps/plano-de-acao-para-o combate-a-erosao-da-base-tributaria-e-a-transferencia-de-lucros-9789264207790-pt.htm

$47 \operatorname{COM}(2013) 814$ final.

${ }^{48}$ A questão da cláusula geral antiabuso, surge em 2015 por via da aprovação da Diretiva (UE) 2015/121 do Conselho, de 27 de janeiro de 2015

49 JO L 359 de 16/12/2014

${ }^{50} \operatorname{COM}(2016) 683$ final.

${ }^{51} \operatorname{COM}(2016) 685$ final.
} 
DOl: $10.46294 /$ ulplr-rdulp.siv lab

Estrangeiras dos Estudos Unidos "Foreign Account Tax Compliance Act"- FACTA). Portanto, o método de tributação assente numa base comum de consolidada ("Common (Consolidated) Base Taxation), tem sido a base de trabalho que ao longo dos últimos anos tem vindo no seio da EU a ajudar a remover importantes obstáculos à coordenação da fiscalidade europeia das empresas, acelerada hoje após a concretização do Brexit.

Na realidade, aguarda-se em 2022, que no espaço da EU e em resultado da evolução dos diversos trabalhos decorrentes do plano de ação BEPS, quer quanto ao alargamento da base da matéria coletável comum a empresas e sociedades com mais de 750 milhões de euros de receita consolidada, quer quanto ao combate e evasão fiscal, através da consagração de uma exigência obrigatória e não facultativa - Base Fiscal Única Harmonizada Obrigatória, evitando receitas extraordinárias assentes na manipulação de preços de transferência ${ }^{50}$, por exemplo (Ribeiro, 2021).

Os avanços já conquistados, por via da redução de custos administrativos e parafiscais, da existência de um balcão único para tratamento das matérias empresariais fiscais, quer pelo afastamento dos preços de transferência dentro do mesmo grupo empresarial ou da definição de critérios relativos aos métodos da subcapitalização e imputação de lucros das sociedades não residentes, para além das questões das compensações e transferências de prejuízos no seio do mesmo grupo, ou entre filiais e sucursais e a empresa mãe que integram ${ }^{51}$.
Na verdade, as soluções encontradas até agora no contexto do BEPS por via de um padrão internacional de troca de informações fiscais e a resposta europeia por via da aprovação da Diretiva antiabuso, podem potenciar um regime jurídico básico para a coexistência de diferentes regimes fiscais nacionais, mas a insegurança jurídica aumentará face da intensificação da globalização das relações económicas e da persistente interpretação restritiva das regras dos Tratados pela União Europeia.

É certo, que estas iniciativas legislativas são matéria de difícil consensualização na EU, pois contendem com o núcleo essencial dos poderes ínsitos à soberania fiscal nacional de cada Estado, o que exige um grande esforço de aproximação e harmonização no âmbito do Conselho, após parecer positivo do PE, como por exemplo acontece hoje com as matérias relativas à forma de determinação do lucro das empresas e ao conceito de grupo empresarial, no que concerne à variação das receitas fiscais nacionais. 
DOI: $10.46294 /$ ulplr-rdulp.siv lab

\section{Bibliografia}

AAVV. 15 Anos da Reforma Fiscal de 1988/89 (2005), Jornadas de Homenagem ao Professor Doutor Pitta e Cunha, AFP/IDEFF (orgs.), Coimbra.

Brauner, Yariv (2014), "BEPS: Na Interim Evaluation", World Tax Journal, n. 1.

Cédelle, Anzhela (2015), «Enhanced cooperation: A way forward for tax harmonisation in the EU??», Working paper series, Oxford University Centre for Business Taxation,

October, disponivel em

Https://www.sbs.ox.ac.uk/sites/default/files/Business_Taxation/Docs/Publications/Working_Papers/Series_15/WP1533b.pdf. , pp. 2 e ss.

COM (2001), A política fiscal da União Europeia: prioridades para os próximos anos, 25.05.2001.

COM (97), Rumo a uma coordenação em matéria fiscal na União Europeia, de 1.10.1997.

Comissão Europeia "Um estudo analítico da fiscalidade das empresas na Comunidade Europeia" (SEC(2001)1681).

Conceição, Pedro, eds., The new public finance: responding to global challenges, New York, Oxford University Press.

De Grauwe, Paul (2006), "What we Learnt about Monetary Integration since the Maastricht Treaty?", JCMS: Journal of Common Market Studies, Vol. 44.

Devereux, Michael P. e Lorety, Simon (2009), "Qu'est-ce que la concurrence fiscale et comment se manifest-telle?", Stratégies Fiscales des Etats et des Entreprises:

Souveraineté et concurrence, Paris, PUF.

Dourado, Ana Paula (2016), "The EU Anti Tax Avoidance Package: Moving Ahead of BEPS?", Intertax, n. ’s 6-7.

Dourado, Ana Paula (2018), Governação Fiscal Global, 2. ${ }^{a}$ Edição, Almedina

Dourado, Ana Paula (2021), Direito Fiscal, 6. Edição, Almedina.

Khan Niazi, S., \& Krever, R. (2015), Is integration of income taxation possible in the EU? Australian Tax Forum, 30(2), 455-470.

Marques, Ana (2017), A concorrência fiscal e a Integração Europeia. Evolução e desafios, FDUL.

Mateus, Abel M. (2003), A Teoria Económica e as Concentrações na perspetiva da Política da Concorrência, Coimbra, 3 outubro de 2003, Lição Inaugural proferida na Faculdade de Direito da Universidade de Coimbra, in https://www.researchgate.net/publication/255611864

Mateus, Abel M. (2006), "Sobre os fundamentos do Direito e Economia da Concorrência", Revista da Ordem dos Advogados, Ano 2006, Vol. III, Dez., em www. portal.oa.pt

Mclure, Charles E. (2001), "Globalization, tax and national sovereignty", Jr. Bulletin Contents, vol. 55, n. ․ 8, IBFD.

Motta, Massimo (2003), Competition Policy: Theory and Pratice, Cambridge U.P., Cambridge.

Musgrave, Peggy B. (2006), "Combining fiscal sovereignty and coordination: national taxation in a globalizing world", in Kauk, Inge.

Nabais, José Casalta (2008), Por um Estado Fiscal Suportável - Estudos de Direito Fiscal, Vol. II, Coimbra, Almedina.

Nabais, José Casalta (2015), Introdução ao Direito Fiscal das Empresas, 2. edição, Coimbra, Almedina.

OCDE (1998), Harmful Tax Competition, Paris.

OCDE/OECD (1987), International Tax avoidance and Evasion - Four relevant studies, Paris.

Palma, Clotilde Celorico, "A OCDE, a concorrência fiscal prejudicial e os Paraísos Fiscais: novas formas de discriminação fiscale", Revista de Ciência e Técnica Fiscal, n. 403.

Pereira, Paula Rosado (2004), A tributação das sociedades na União Europeia - Entraves fiscais ao mercado interno e estratégias da atuação comunitária, Coimbra, Almedina. 
DOI: 10.46294/ulplr-rdulp.sivlab

Pires, Rita Calçada (2019), Manual de Direito Internacional Fiscal, Almedina.

Pollack, Mark A. (2003), The Engines of European Integration: delegation, Agency and Agenda-Setting in the EU, New Yoirk: Oxford University Press.

Pollack, Mark A. (2008), "The New Institutionalism and European Integration", Webpappers on Constitucionalism \& Governance beyond the State, www.bath.ac.uk/ esml/conWEB, Issn:1756-7556;

Quadros, Fausto (2004), Direito da União Europeia, Coimbra, Almedina, p. 445.

Rassat, Patrick, Thierry Lamonlette e Cameli Thibault (2010), Strategies Fiscales Internacionales, Paris: Maxime.

Ribeiro, João Sérgio (2021), Direito Fiscal da União Europeia, 2. ${ }^{a}$ Edição, Almedina, p. 20.

Saldanha Sanches, J. L. (2012), Manual de Direito Fiscal, 2. ${ }^{a}$ Edição, Coimbra, Coimbra Editora.

Rocha Andrade, F. (2001), "Concorrência fiscal e concorrência fiscal prejudicial na tributação direta do capital», Boletim de Ciências Económicas, Vol. XLIV.

Santos, António Carlos, "Concorrência Fiscal e Competitividade - A Never Ending Story", Ciência e Técnica Fiscal, n. 424.

Silva, Miguel Zuzarte Ferreira da (2017), O Brexit e o seu efeito no processo de harmonização Fiscal da União Europeia, Dissertação de Mestrado, ISCTE.

Tanzi, Vito (2017), Termites of the State, Cambridge University Press.

Tratado de Lisboa. www.dgeg.gov.pt.

Wasserfallen, Fabio (2014), "Political and Economic Integration in the EU: The Case of Failed Tax Harmonization", JCMS: Journal of Common Market Studies, Vol. 52. 